\title{
INITIALLY SYNTHESIZE [BMIM]CL AND APPLY TO EXTRACT CELLULOSE FROM BANANA RACHIS
}

\author{
An T.T. Tran ${ }^{1 *}$, Huy T. Vo ${ }^{2}$, Quan D. Nguyen ${ }^{3}$ \\ ${ }^{1}$ Laboratory of Biofuel and Biomass Research \\ 1,2,3, *Ho Chi Minh University of Technology, Vietnam \\ Email: trantuongan@hcmut.edu.vn,trantuongan81@gmail.com
}

*Corresponding Author: -

Email: trantuongan@hcmut.edu.vn,trantuongan81@gmail.com

\begin{abstract}
: -
Ionic liquors are organic salts with cations as organic and anionic inorganic bases, which exist in a viscous liquid state than organic solvents.

The banana rachis is one of the agricultural products from banana trees. In Vietnam, bananas are high yield fruit trees. The amount of debris from banana trees is quite large but not yet utilized effectively to bring economic value.

Banana rachis material is utilized and treated with 1-butyl-3-methylimidazolium chloride ([BMIM]Cl) ionic liquid to initially investigate the ability of cellulose to separate the ionic liquid from the banana rachis.

Banana rachis processing by [BMIM]Cl was investigated at $80^{\circ} \mathrm{C}, 100^{\circ} \mathrm{C}, 120^{\circ} \mathrm{C}$ and $140^{\circ} \mathrm{C}$ for 1 hour. Then analyze the reducing sugar and cellulose ingredients in the banana rachis samples. The results showed that the optimum temperature for banana rachis processing with [BMIM]Cl is $140^{\circ} \mathrm{C}$ for 1 hour.

Ionic liquid in general and [BMIM]Cl in particular have great potential in the processing of fruit waste. Specifically, the content of cellulose in the banana kernel after treatment [BMIM]Cl was 73.04 $\pm 7.49 \%$ compared to untreated sample was $26.25 \pm 1.43 \%$, 3 times higher.

The results of FTIR of banana rachis and recycled [BMIM]Cl showed that the lignin component in the banana rachis was quite soluble, resulting in a significant increase in cellulose content.
\end{abstract}

Keywords: Banana rachis, Musa acuminata, cellulose, ionic liquid, [BMIM]Cl

\section{(우 (\$) (1)}




\section{INTRODUCTION}

The main constituent of agricultural by-products is lignocellulose. In order to produce bio-energy from agricultural waste, cellulose must be converted into waste products into single glucose. However, lignocellulose is a complex structure containing cellulose, hemicellulose and lignin. These complexes are difficult to break down into individual polymer and monomer components, so converting biomass into sugars becomes difficult, energy-intensive and costly.

Therefore, in order to make good use of waste products, pre-production of bio-energy requires enrichment and separation of cellulose from lignocellulose by pre-treatment methods. Preprocessing is the process required to break down the lignocellulosic structure, remove hemicellulose, break down lignin, reduce the crystallization of cellulose and enrich the cellulose content of the biomass.

There are many ways to enrich cellulose from raw biomass sources such as chemicals, enzymes or microorganisms. In particular, ionic liquids are the most researched currently available because they are safe, highly recyclable, and have less environmental impact than other chemicals.

Currently, scientists have studied and concluded that there are about 20 types of ionic liquids that can handle lignocellulose, including ionic liquid (IL) that dissolve cellulose, dissolve lignin and dissolve hemicellulose, including [BMIM]Cl.

In order to study the potential of $[\mathrm{BMIM}] \mathrm{Cl}$ cellulose removal from lignocellulose waste, conducted research on $[\mathrm{BMIM}] \mathrm{Cl}$ and pulp waste as banana rachis.

\section{MATERIALS AND METHODS}

\section{A. Raw materials}

Banana (Musa acuminata) rachis were harvested at confectionery processing factories in Ho Chi Minh city, Vietnam. The grounded peel was then dried in a dryer oven at $140^{\circ} \mathrm{C}$ for 1 h to reach the moisture content of $5 \pm 0.5 \%$. Subsequently, the dehydrated rachis was grounded to powder by food processor (Phillip, Holland) and packed polyethylene bags, sealed and stored at $4^{\circ} \mathrm{C}$. These treated rachides were used for cellulose extraction.

\section{B. Methods}

\section{1) Chemical Analysis:}

Research some chemical composition of banana peel which includes: 1) moisture content (was determined by infrared dryer Mettler Toledo, at $108^{\circ} \mathrm{C}$ ), 2) total soluble solids (was determined by Atago digital refractometer, Japan), 3) pH (was determined by Hanna instrument), 4) reducing sugar content (using DNS reagent, as Miller method) [5], 6) cellulose content [4] and 7) lignin content (as Klason method), FTIR and SEM.

\section{2) Synthesize [BMIM]Cl ${ }^{T H}$}

Weigh 20 gram of 1methylimidazole, 46 gram 1-chlorobutane and $50 \mathrm{~mL}$ acetone into the flask. Perform reaction at 55 $70^{\circ} \mathrm{C}$, for 100 hours, on a stove from a thermostat. Upon completion of the reaction, the vessel was vacuumed and washed several times with ethyl acetate and ethanol. Crystallization of the product at low temperature in the solvent ethanol and ethyl acetate. Crystalline preservation [BMIM]Cl in ethyl acetate. Preserve crystal [BMIM]Cl in ethyl acetate.

\section{3) Treat Banana Rachis with [BMIM]Cl ${ }^{\mathrm{TH}}$}

Weigh 1.5 grams [BMIM]Cl ${ }^{\mathrm{TH}}$ into a balloon containing 0.025 gram of raw material.

Mixing ingrediens and $[\mathrm{BMIM}] \mathrm{Cl}^{\mathrm{TH}}$ are stirred on a stirrer from a thermostat, $500 \mathrm{rpm}, 140^{\circ} \mathrm{C}$ for 1 hour. After treatment, the mixture is cooled to room temperature. Then wash the mixture with hot distilled water $\left(80^{\circ} \mathrm{C}\right)$ as follow: add $10 \mathrm{~mL}$ hot water to the mixture and stir from the stirrer at $500 \mathrm{rpm}$ and $80^{\circ} \mathrm{C}$ for 1 hour. Filter and rinse the mixture several times and recover the filtered water. The residue and filtrate are diluted to the appropriate concentration and analyzed. Repeat the experiment 3 times for each sample.

Perform treating experiment with Sigma Aldrich [BMIM]Cl ([BMIM]Cl $\left.{ }^{\mathrm{TM}}\right)$ Samples:

\section{[BMim] $\mathrm{Cl} \mathrm{TM}$}

- K-2: dried banana rachis - X-B1: K-2 $\longrightarrow$ Mẫu X-B1

- X-B1D: recovery solution from rinsing X-B1

[BMim] Cl TH

- X-B2: K-2 $\longrightarrow$ Mẫu X-B2 - X-B2D: recovery solution from rinsing X-B2

\section{RESULTS AND DISCUSSES}

A. Chemical Composition of Banana rachis 


\section{TABLE I}

CHEMICAL COMPOSITION OF BANANA RACHIS

\begin{tabular}{|c|c|c|c|}
\hline Composition & Content & Composition & Content \\
\hline e (\%) & $82 \pm$ & Pectin (\%) & $1.33 \pm$ \\
\hline $\mathrm{e}(\%)$ & 2.16 & & 1.1 \\
\hline Ash (\%) & $1.37 \pm$ & Total acidity (\%) & $0.14 \pm$ \\
\hline Cellulose (\%) & $\begin{array}{r}9.5 \pm \\
0.01\end{array}$ & $\begin{array}{l}\text { Reducing sugar } \\
(\mathrm{mg} / \mathrm{g})\end{array}$ & $\begin{array}{r}1.08 \pm \\
0.017\end{array}$ \\
\hline Lignin (\%) & $\begin{array}{r}3.12 \pm \\
0.5\end{array}$ & $\begin{array}{l}\text { Peel content } \\
(\mathrm{g} / 100 \mathrm{~g})\end{array}$ & $\begin{array}{r}15.23 \pm \\
2.13\end{array}$ \\
\hline
\end{tabular}

The chemical composition of banana peel is presented in Table 2. The data indicated that the banana peel is a rich source of sugars, total acidity and total soluble solids content. The dried banana peel contained high amount of reducing sugars (up to $89.43 \mathrm{mg} / \mathrm{g}$ ) and the results are similar to those of previous reports ([6],[7]). The high cellulose content of banana peel could serve as the important source for bioethanol fermentation use microbial culture. B. Synthesize [BMIM]Cl

After synthesis, [BMIM]Cl ${ }^{\mathrm{TH}}$ is in white crystalline form as shown in Fig.1. However, the [BMIM]Cl ${ }^{\mathrm{TH}}$ obtained was not completely homogeneous; some "watery" spots due to [BMIM] $\mathrm{Cl}^{\mathrm{TH}}$ have absorbed moisture from the air. Therefore, the ionic liquid obtained is not purified.
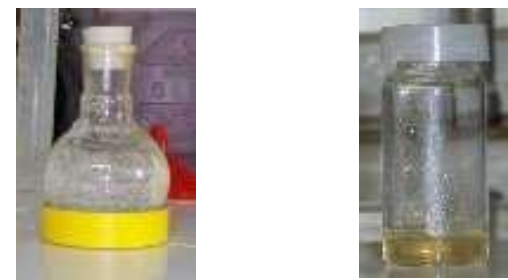

Fig.1. [BMIM]Cl ${ }^{T H}$

\section{Treat Banana Rachis With [BMIM]CL ${ }^{\text {TH }}$ To Extracting Cellulose}

From the Banana Core Temperature Survey, select the optimum temperature to separate cellulose by [BMIM]Cl.

\section{i) Solibility}

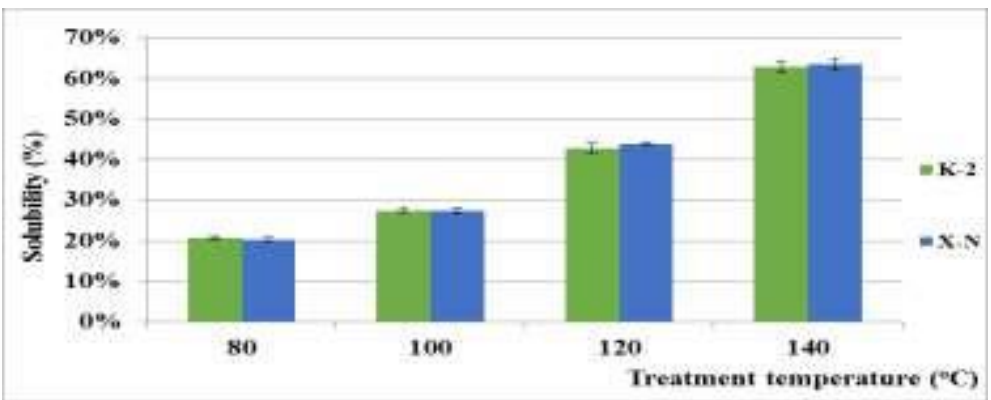

Fig.2. Effect of temperature to solibility of $\mathrm{K}-2$ and $\mathrm{X}-\mathrm{N}$ samples in [BMIM]Cl

The solubility of the K-2 and X-N samples in [BMIM]Cl increased with treating temperature (Fig 2). [BMIM]Cl exists in the crystalline state and begins to melt at $70^{\circ} \mathrm{C}$. In order to experiment smoothly, the lowest survey temperature was set at $80^{\circ} \mathrm{C}$. The highest survey temperature is $140^{\circ} \mathrm{C}$ because at temperature higher than $140^{\circ} \mathrm{C}$, some organic components will decay or coalize.

Therefore, the optimum dissipation temperature of the banana core samples in [BMIM]Cl was $140^{\circ} \mathrm{C}$ (solubility was $62.78-1.36 \%$ with $\mathrm{K}-2$ and $63.45-1.39 \%$ with $\mathrm{X}-\mathrm{N})$.

\section{ii) Reducing sugar content}

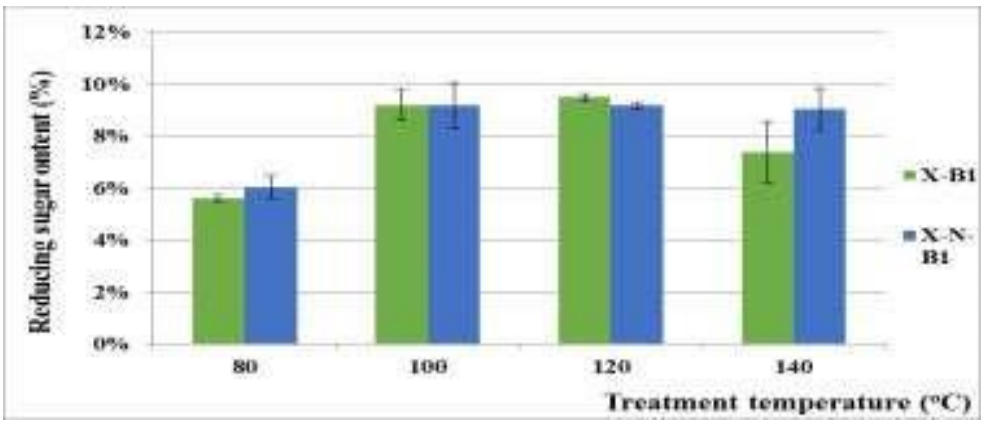

Fig 3. Effect of temperature to reducing sugar content in [BMIM]Cl ${ }^{\text {TH }}$ treated samples 
Treating banana rachis samples (sample X-B1 and sample X-N-B1) with [BMIM]Cl, reducting sugar content in increased gradually with temperature (Fig 3). However, when the temperature was higher than $120^{\circ} \mathrm{C}$, sugar content decreased (from $9.49 \pm 0.14 \%$ to $7.37 \pm 1.19 \%$ for sample X-B1 and from $9.17 \pm 0.15 \%$ to $9.03 \pm 0.78 \%$ for sample X-N-B1).

The cause is:

- At temperatures above $120^{\circ} \mathrm{C}$, sugar molecular begins to denature.

- In addition to soluble sugar, [BMIM]Cl also dissolves other ingredients such as cellulose, lignin, inorganic particles... so the activity of [BMIM]Cl weak gradually.

- Random errors and system errors during analysis.

iii) Cellulose content

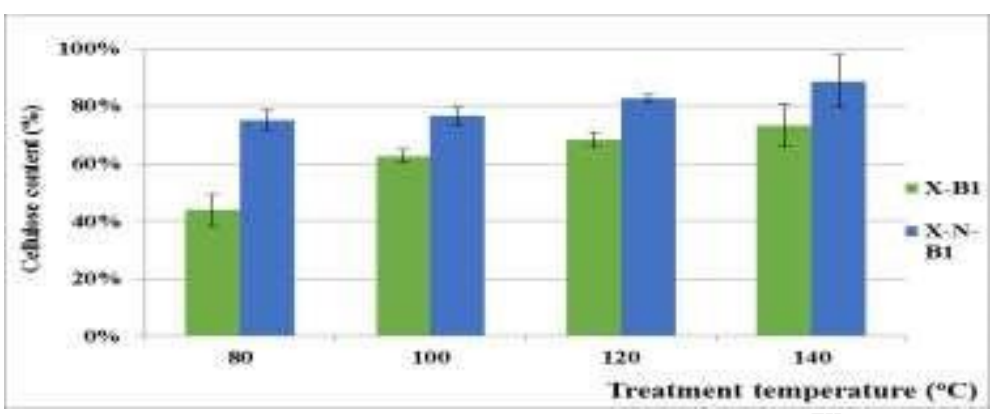

Fig 4. Effect of temperature to cellulose content in [BMIM]Cl ${ }^{T H}$ treated samples

Temperature was studied in range from $80^{\circ} \mathrm{C}$ to $140^{\circ} \mathrm{C}$. The cellulose content of $\mathrm{X}-\mathrm{B} 1$ and $\mathrm{X}-\mathrm{N}$-B1 increased when treatment temperature increased (Fig 3).

The cellulose content of X-B1 increase slighter than the other. When rising temperature from $80^{\circ} \mathrm{C}$ to $100^{\circ} \mathrm{C}$, the cellulose content increased $18.61 \%$, continue rising from $120^{\circ} \mathrm{C}$ to $140^{\circ} \mathrm{C}$, the cellulose content increased $4.67 \%$. Oppsite to the $\mathrm{X}$ $\mathrm{N}-\mathrm{B} 1$, rising temperature from $80^{\circ} \mathrm{C}$ to $100^{\circ} \mathrm{C}$, cellulose content increased $1.27 \%$, and from $120^{\circ} \mathrm{C}$ to $140^{\circ} \mathrm{C}$, the cellulose content increased $5,80 \%$. The cause of difference was due to X-B1 came from K-2, which was raw with high lignin content. When preparing K-2 with [BMIM]C1, the lignin was maximum dissolved, this lead to an increase in the initial cellulose content. For sample X-NB1, most of lignin was removed with $\mathrm{NaOH} 5 \mathrm{~N}$, so when treated with [BMIM]C1, the remaining lignin was very little and was dissolved in [BMIM]C1 resulting in cellulose content slight increase. When the temperature rose to $140^{\circ} \mathrm{C}$, [BMIM]Cl fully melt, "năng lực hòa tan" of [BMIM]Cl increase, so that cellulose content increased more rapidly than initially. However, the increase of cellulose in X-N-B1 was much lower than X-B1.

As the result, the optimum cellulose content of X-B1 was $73.04 \pm 7.49 \%$ and of $\mathrm{X}-\mathrm{N}-\mathrm{B} 1$ was $88.50 \pm 9.16 \%$ at temperature $140^{\circ} \mathrm{C}$. The content of reducing sugar and cellulose in sample X-B1 and X-N-B1 under the temperature, the optimum temperature for extraction of cellulose by $[\mathrm{BMIM}] \mathrm{Cl}$ was $140^{\circ} \mathrm{C}$.

\section{Compare Cellulose Extractions From Banana Rachis Between Treating By [BMIM]Cl ${ }^{T H}$ And [BMIM]Cl ${ }^{T M}$ i) Reducing sugar and cellulose content of banana rachis solution}

$[\mathrm{BMIM}] \mathrm{Cl}$ after synthesis was used for cellulose separation experiments, compared with the $[\mathrm{BMIM}] \mathrm{Cl}^{\mathrm{TM}}$ cellulose extraction. Comparison of reducing sugar and cellulose content of samples after treatment with $[\mathrm{BMIM}] \mathrm{Cl}^{\mathrm{TH}}$ and $[\mathrm{BMIM}] \mathrm{Cl}^{\mathrm{TM}}$ is shown in Fig.5.

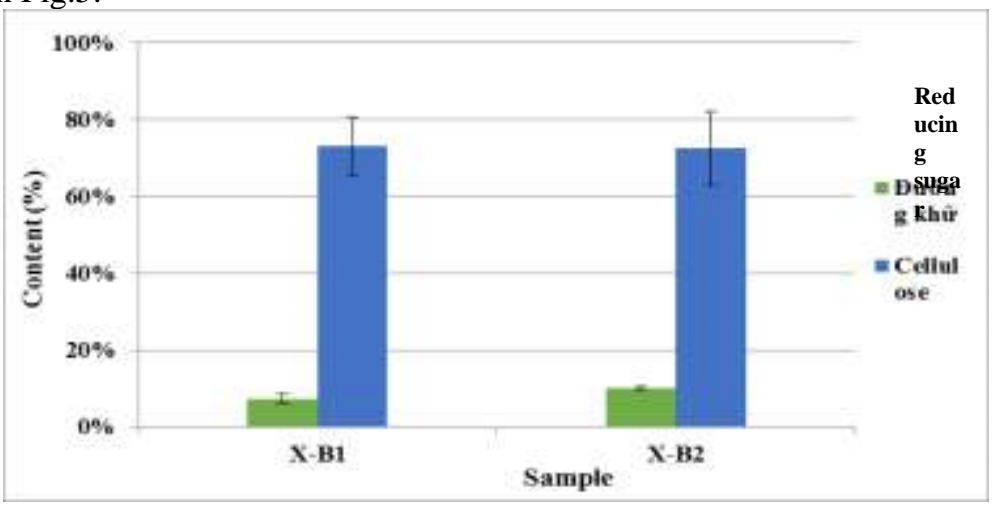

Fig.5. Reducing sugar and cellulose content of banana rachis solution after treated with $[\mathrm{BMIM}] \mathrm{Cl}^{\mathrm{TH}}$ và $[\mathrm{BMIM}]^{\mathrm{TM}}$

According to the analysis results, the effective of using [BMIM] $\mathrm{Cl}^{\mathrm{TH}}$ to extract cellulose from banana rachis lignocellulose was slightly different than from [BMIM] $\mathrm{Cl}^{\mathrm{TM}}$ (cellulose content in sample X-B2 was $72.40 \pm 9.56 \%$; in sample X-B1, it was $73.04 \pm 7.49 \%$, difference $0.64 \%$ ).

However, the results of reducing sugar content showed that the reducing sugar content in sample $\mathrm{X} \square \mathrm{B} 2$ was $10.05 \square 0.42 \%$, higher than sample X-B $1(7.37 \square 1.19 \%)$. The reason is [BMIM] $\mathrm{Cl}^{\mathrm{TH}}$ has many impurities, including water, which facilitates the separation of more reducing sugars. 
Although in the synthesis process there are many limitations, the sample $[\mathrm{BMIM}] \mathrm{Cl}^{\mathrm{TH}}$ is impure, but the separation capacity of $[\mathrm{BMIM}] \mathrm{Cl}^{\mathrm{TH}}$ is not much difference $[\mathrm{BMIM}] \mathrm{Cl}^{\mathrm{TM}}$ and higher economic efficiency. Including synthetic cost, solvent and refined chemicals, the cost to synthesize $100 \mathrm{~g}$ [BMIM]Cl performance $48-52 \%$ is only about $30-40 \mathrm{USD} / \mathrm{kg}$. Meanwhile, pure [BMIM]Cl ${ }^{\mathrm{TM}}$ is listed on the market at $\$ 585.99 / \mathrm{kg}$. This leads to higher cellulose separation costs by $[\mathrm{BMIM}] \mathrm{Cl}^{\mathrm{TM}}$ than $[\mathrm{BMIM}] \mathrm{Cl}^{\mathrm{TH}}$.

ii) Reducing sugar and cellulose content of recycled [BMIM]Cl

As result in Fig.6, [BMIM]Cl ${ }^{\mathrm{TH}}$ also partially dissolved cellulose and reducing sugars. However, the cellulose solubility of $[\mathrm{BMIM}] \mathrm{Cl}^{\mathrm{TH}}$ is lower than $[\mathrm{BMIM}] \mathrm{Cl}^{\mathrm{TM}}$. The cellulose content in the $\mathrm{X}-\mathrm{B} 2 \mathrm{D}$ sample was $6.69 \pm 1.18 \%$, lower than $5.33 \%$ in $\mathrm{X}-\mathrm{B} 1 \mathrm{D}$ sample. The cause is that $[\mathrm{BMIM}] \mathrm{Cl}^{\mathrm{TH}}$ contains impurities that interfere with the dissolution of cellulose.

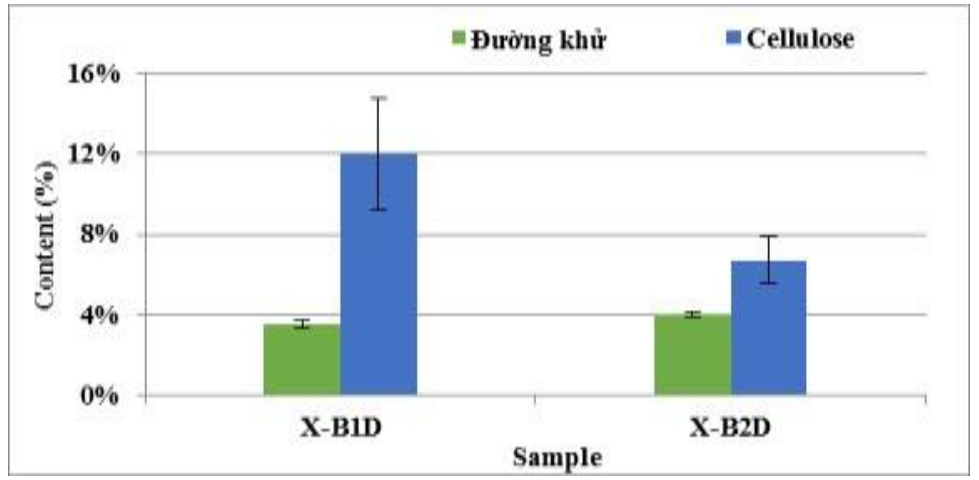

Fig.6. Reducing sugar and cellulose content in recycled [BMIM]Cl after treating banana rachis

\section{E. FTIR Diagram}

\section{i) FTIR diagram of $[\mathrm{BMIM}] \mathrm{Cl}^{\mathrm{TH}}$}

The FTIR diagram identifies the characteristics of group and the chemical bond in a compound. From which can specify a complex structure of the compound.

Fig.7. shows, at $3349 \mathrm{~cm}^{-1}$ corresponds to the tip of the $[-\mathrm{OH}]$ containing hydrogen bond, which demonstrates that $[\mathrm{BMIM}] \mathrm{Cl}$ contains water, due to the nature of the easily absorbed ionic liquid.

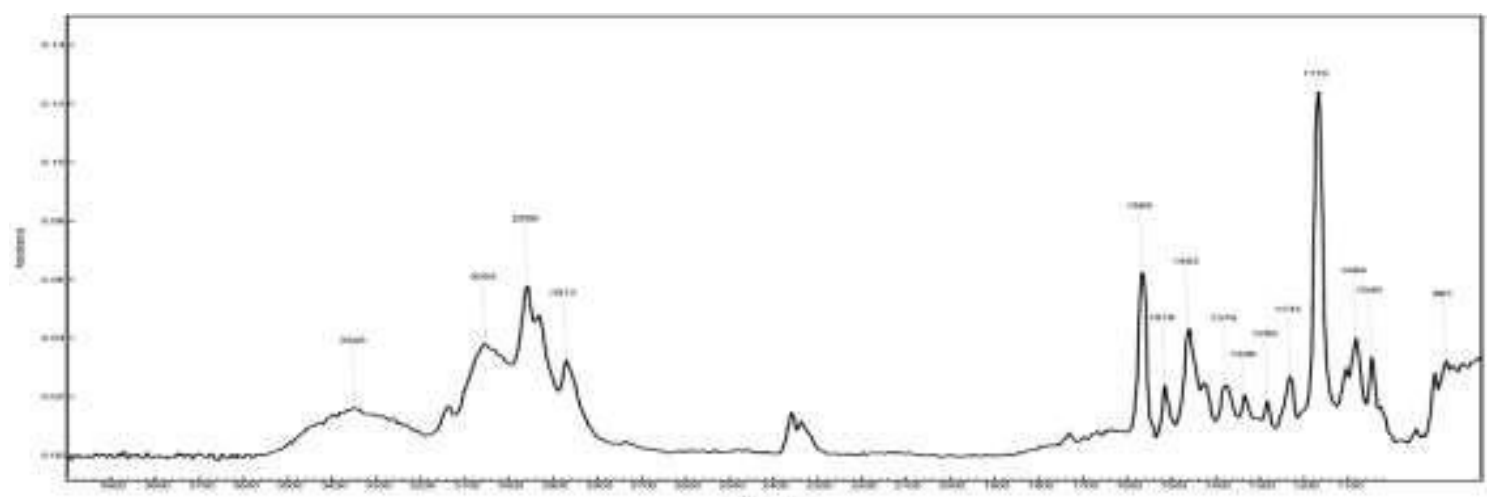

Fig.7. FTIR diagram of [BMIM]Cl ${ }^{T H}$

[BMIM]Cl molecular contains cation $[\mathrm{BMIM}]^{+}$, at $2958 \mathrm{~cm}^{-1}$ corresponds to asymmetrical bond C-H; The frequency of $2872 \mathrm{~cm}^{-1}$ corresponds to the symmetrical bond $\mathrm{CH}$; frequency of $1569 \mathrm{~cm}^{-1}$ corresponds to the absorption peak of $\mathrm{C}=\mathrm{N}$ groups within imidazole ring; The frequency of $1518 \mathrm{~cm}^{-1}$ corresponds to the absorption peak of the $\mathrm{C}=\mathrm{C}$ bond within imidazole; frequency $1463 \mathrm{~cm}^{-1}$ corresponds to $\left[-\mathrm{CH}_{3}\right]$ oscillation distortion in the plane; frequency of $1170 \mathrm{~cm}^{-1}$ corresponds to the oscillation of the group concentration of the imidazole ring and the alkyl residues $\left(\left[-\mathrm{CH}_{3}\right]\right.$ and $\left[-\mathrm{C}_{4} \mathrm{H}_{9}\right]$ on both sides of the imimdazole ring); the frequency of $881 \mathrm{~cm}^{-1}$ corresponds to the oscillation of the imidazole ring.

ii) FTIR diagram of [BMIM] $\mathrm{CI}^{\mathrm{TH}}$ treated banana rachis samples to extract cellulose Fig.8. (a) shows FTIR analysis results of sample K2. At $3332 \mathrm{~cm}^{-1}$, the absorption peak of -OH group containing hydrogen bond characteristic of cellulose and hemicelluose. At $2922 \mathrm{~cm}^{-1}$ characterizes the oscillation of asymmetric CHO group. Peak $1621 \mathrm{~cm}^{-1}$ is obtained from the oscillation of the groups of aromatic rings in the characteristic plane of lignin. Peak 1410 and $1240 \mathrm{~cm}^{-1} \mathrm{correspond}$ to the oscillation of the $-\mathrm{CH} 3$ group deformed in the plane. The absorption of the - $\mathrm{CH} 3$ deformation group was approximately $1316 \mathrm{~cm}^{-1}$ Frequency of $1032 \mathrm{~cm}^{-1}$ corresponds to the fluctuations of the characteristic $\mathrm{C}_{2}$ bond of lignin and hemicellulose, and at $898 \mathrm{~cm}^{-1}$ is the absorption peak of the $\mathrm{C}-\mathrm{O}-\mathrm{C}$ group which is characterized by the $\beta-1$ bond, 4 glycoside in the structure of cellulose. 


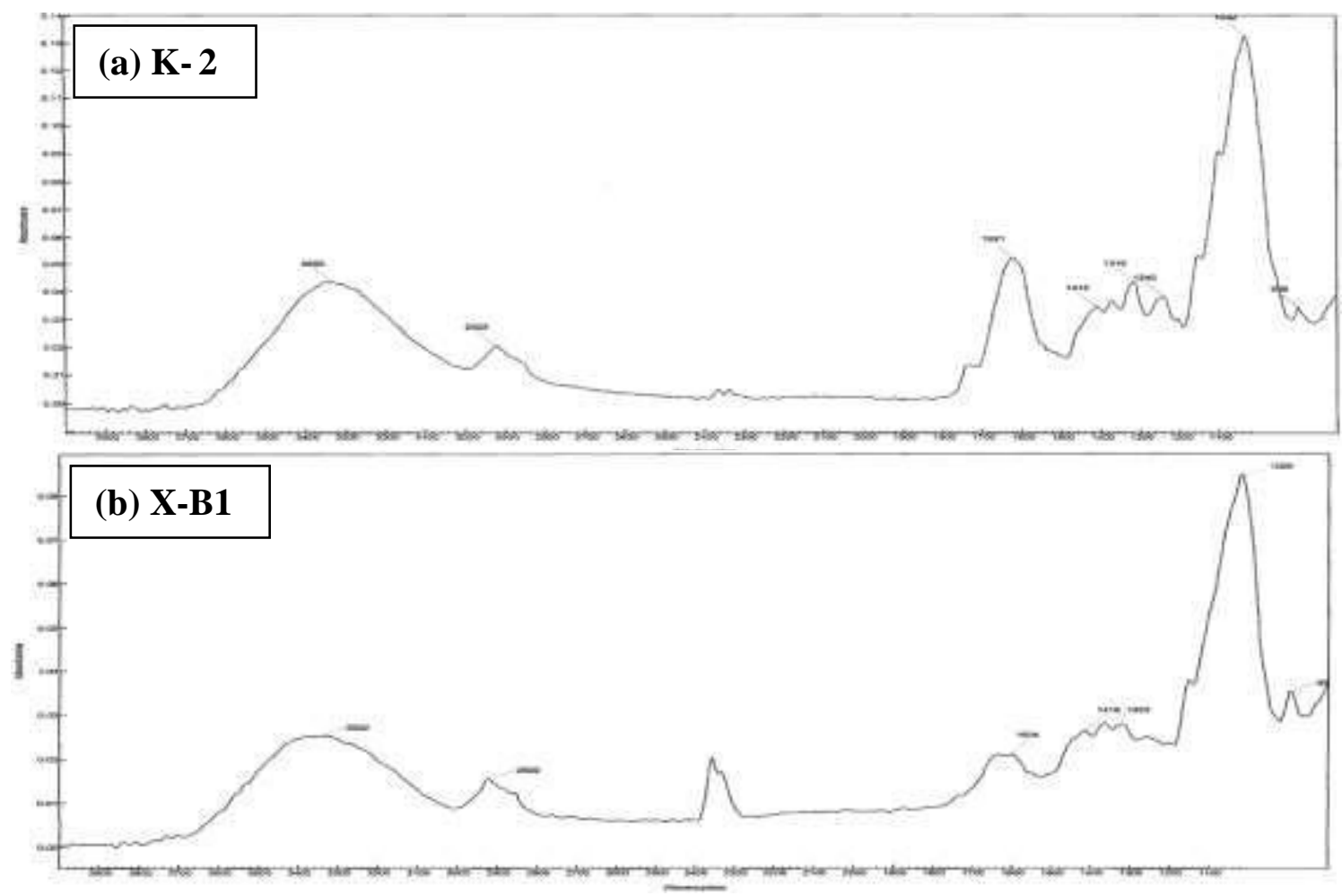

Fig 8. FTIR diagram of $\mathrm{K}-2$ and $\mathrm{X}-\mathrm{B} 1$

Comparing Fig.8 (a) and (b):

After treating $\mathrm{K} 2$ sample with [BMIM]Cl ${ }^{\mathrm{TM}}$, the bond between lignin-cellulose, hemicellulose-cellulose molecules are destroyed, the sensitivity to $\beta-1,4$-glycoside in cellulose molecules increases. Specifically, the absorption of [-OH] is markedly reduced (0.044-0.023); absorption of C-O-C bond increased (0.034-0.038). The lignin content decreased significantly, the absorption of $\mathrm{C}-\mathrm{H}$ group within lignin aromatic ring decreased (0.054-023).

However, compared with the $\mathrm{NaOH} 5 \mathrm{~N}$ treatment capacity, $[\mathrm{BMIM}] \mathrm{Cl}^{\mathrm{TM}}$ solibility appear to be weaker. The lignin content was better removed using $5 \mathrm{~N} \mathrm{NaOH}$ (the absorbance of the $\mathrm{CH}$ groups within the lignin aromatic ring was only 0.01). The lignocellulose structure also breaks down better (absorption of [-OH] to 0.009).

With FTIR analysis, it was shown that [BMIM]Cl ${ }^{\mathrm{TH}}$ is capable of breaking down the lignocellulose structure, solubilizing lignin and some other constituents, increasing the cellulose content in banana rachis.

\section{iii) FTIR diagram of [BMIM]Cl ${ }^{\mathrm{TH}}$ recovered after treat banana rachis samples to extract cellulose}

According to the FTIR analysis of the sample X-B1D (Fig.9a), lignin was contained in the [BMIM]Cl ${ }^{\mathrm{TH}}$ solution. Specifically, the peak of C-H oscillation in the lignin aromatic ring $\left(1636 \mathrm{~cm}^{-1}\right)$ appears. Similarly, the FTIR analysis results of the X-N-B1D sample also show the corresponding lignin peak $\left(636 \mathrm{~cm}^{-1}\right)$. However, the absorption of the XN-B1D is 0.027 , higher than the X-B1D (0.018). Cause is due to $\mathrm{NaOH}$ treatment, causing the lignocellulose structure to break, lignin to dissolve.

As for the FTIR analysis of X-B2D samples (Fig.9b), the corresponding peak ligin content was not presented, but the results of the $\mathrm{X}-\mathrm{B} 2$ analysis showed that the lignocellulose treatment of $[\mathrm{BMIM}] \mathrm{Cl}^{\mathrm{TH}}$ is equivalent to $[\mathrm{BMIM}] \mathrm{Cl}^{\mathrm{TM}}$.

Therefore, it is possible to conclude that [BMIM]Cl ${ }^{\mathrm{TH}}$ contains many components. Although [BMIM] ClTH can break down the lignocellulose structure, cellulose composition is quite ideal, but does not dissolve lignin, leaving the cellulose sample intact, unable to remove cellulose from the sample. 

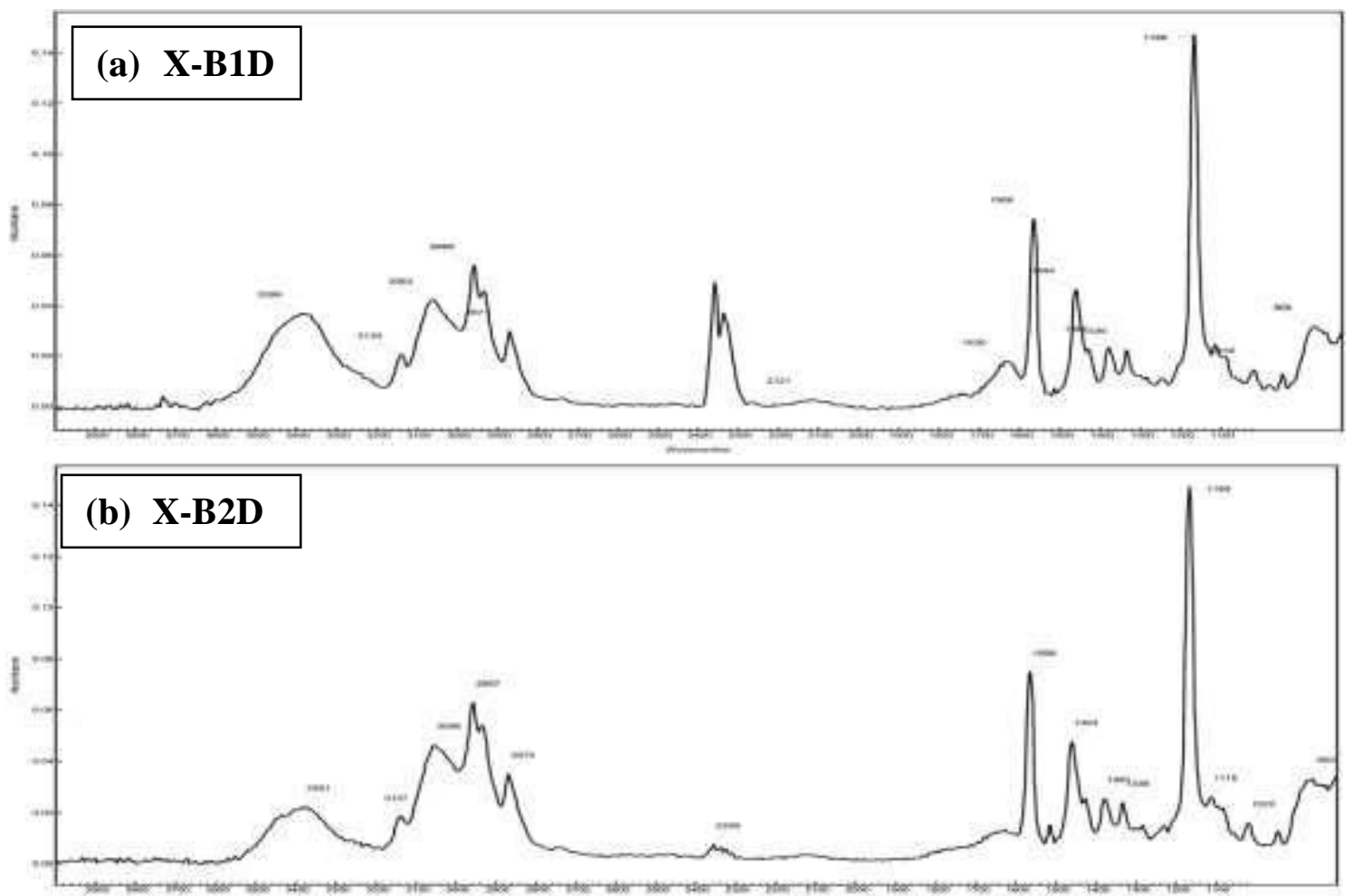

Fig.9. FTIR diagram of $X-B 1 D$ and $X-B 2 D$

\section{E. SEM of Treated Banana Rachis}

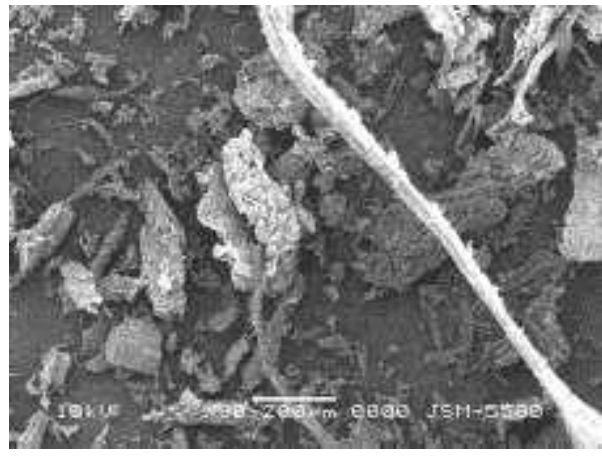

(a) K-2

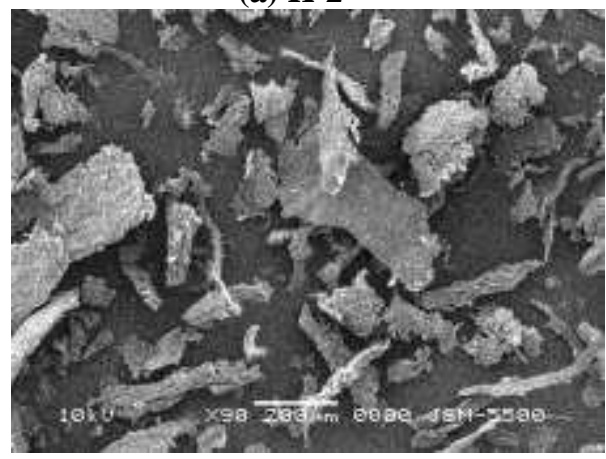

(c) $\mathrm{X}-\mathrm{B} 2$

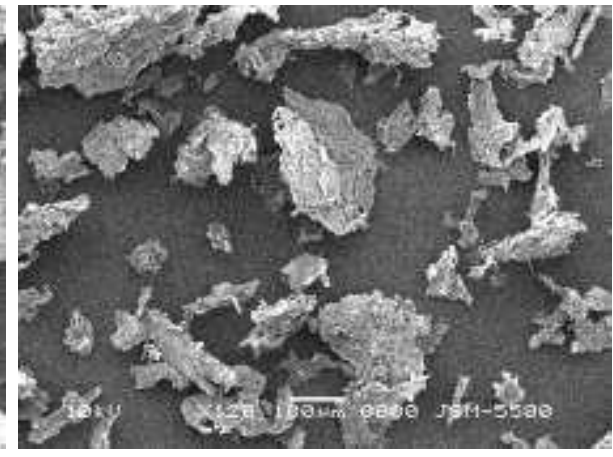

(b) X-B1

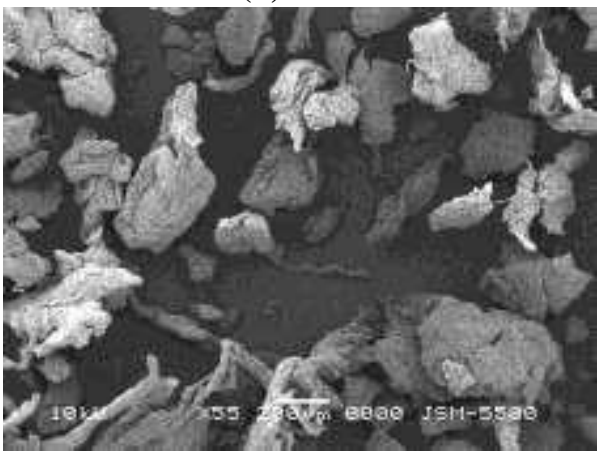

(d) $\mathrm{X}-\mathrm{N}-\mathrm{B1}$

Fig.10. SEM of [BMIM]Cl treated banana rachis samples

As in Fig.10(a), before treatmnt with [BMIM]Cl, banana rachis is quite chaotic structure with many components. After treatment with [BMIM] Cl (Fig.10b) and $\mathrm{NaOH}$ (Fig.10c), components of banana rachis samples are more simply and orderly. This proves that, after treated with [BMIM] $\mathrm{Cl}$ or $\mathrm{NaOH}$, the cellulose content increases, the cellulose link together by the physical bond should be neat and orderly structure. After $\mathrm{NaOH}$ treatment, sample $\mathrm{XN}$ continues to be treated with $[\mathrm{BMIM}] \mathrm{Cl}^{\mathrm{TH}}$ as sample $\mathrm{X}-\mathrm{N} \square \mathrm{B} 1$. According to the results of the SEM of X-N $\square \mathrm{B} 1$ (Fig.10d), most of the impurities have been removed, the main component left in the sample is cellulose, so they are linked together to create a good structure neat and orderly.

From the results of SEM, it can be concluded that $[\mathrm{BMIM}] \mathrm{Cl}^{\mathrm{TH}}$ not only breaks down the lignocellulose structure but also dissolves non-cellulose components, significantly increasing the cellulose content. 


\section{CONCLUSION}

In recent years, handling of IL-rich cellulose wastes has received considerable attention, including fruit waste. Compared to traditional solvents, IL has features such as wide reactive area, temperature stability and negligible vapor pressure. Thanks to its excellent properties, IL gradually becomes a solvent for efficient cellulose separation. They have the ability to separate cellulose from many different types of lignocellulosic biomass. [BMIM] $\mathrm{Cl}^{\mathrm{TH}}$ has the potential to process lignocellulose. [BMIM] Cl is capable of separating more than $70 \%$ of cellulose in lignocellulose from raw banana rachiss (73.04-7.49\%).

Compared to $\mathrm{NaOH}$, the cellulose content is less (less than about 12\%). However, IL is considered to be a greener, safer environment than $\mathrm{NaOH}$, so IL has the potential to be used in lignocellulose treatment. IL has not yet been widely deployed in practice due to some disadvantages. The most notable obstacle is the high cost of chemicals. Although ongoing research confirms that IL is a green, environmentally-friendly solvent, most biomass-treated ILs are nonbiodegradable, requiring a recovery and recycling mechanism. Reasonable use. The toxicity, erosion, and desiccant properties of IL are also concerns. The viscosity of IL is quite high, which is detrimental to cellulose separation. The residual IL in the biomass can inhibit the enzyme during hydrolysis and may be toxic to microorganisms during fermentation.

Despite these obstacles, IL has a promising future for lignocellulosic treatment and the extraction of cellulose from fibrous sources.

\section{ACKNOWLEDGEMENTS}

This research is fund by Vietnam National University HoChiMinh City (VNU-HCM) undergrant number C2015-20-20.

\section{REFERENCES}

[1].Hsieh, W., et al.. 2002. "Engine Performance and Pollutant Emission of an SI Engine Using Ethanol-Gasoline Blended Fuels", Atmospheric Environment Vol. 36, pp. 403410.

[2].Sirkar, A., Das, R., Chowdhury, S., \& Sahu, S.J. (2008). An experimental study and mathematical modelling of ethanol production from banana peels by hydrolysis and fermentation. 88: 4-10.

[3].Jingura RM, Matengaifa R. 2008. Optimisation of biogas production by anaerobic digestion for sustainable energy development in Zimbabwe. Renew. Sustain. Energ. Rev. Article in press.

[4].AOAC, 2000. Association of Official Analytical Chemists. 17th Edn., AOAC, Washington, DC., pp: 21-447.

[5].Miller GC (1959). Use of the Dinitrosalicylic Acid Reagent for the Determination of Reducing Sugar. Analytical Chemists. 31: $420-428$.

[6].Anonymous (2004). By-products and waste utilization (value addition of mango processing waste). Food Digest. 27: 14-17.

[7].Madhukara K, Krishnanad N, Srilatha HR (1993). Ensilage of mango peel for methane generation. Process Biochem., 28: 119-123.

[8].Sirkar, A., Das, R., Chowdhury, S., \& Sahu, S.J. (2008). An experimental study and mathematical modelling of ethanol production from banana peels by hydrolysis and fermentation. 88: 4-10.

[9].Patle, S.,\& Lal, B. (2007). Ethanol production from hydrolysed agricultural wastes using mixed culture of and . 29: 18391843.

[10]. Singh, A., Das, K., \& Sharma, D.K.(1984). Production of Xylose, furfural, fermentable sugars and ethanol from agricultural residues. 34A: 5161.

[11]. B.C. Akin-Osanaiye, H.C. Nzelibe and A.S. Agbaji. 2008. Ethanol production from Carica papaya (paw paw) fruit wate, Asian journal of Biochemistry, 3(3), 188-193.

[12]. S.L.Hii, T.Y.Ding and L.G.A. Ong. 2010. Comparative Evaluation of Pretreatment strategies on enzymatic saccharification of Hylocereus polyrhizus's pericarps for bioethanol production, Iranica Journal of Energy \& Environment 1(4): 275-279.

[13]. Lebaka Veeranjaneya Reddy, Obulam Vijaya Sarathi Reddy2 and Young-Jung Wee. 2011. Production of ethanol from mango (Mangifera indica L.) peel by Saccharomyces cerevisiae CFTRI101, African Journal of Biotechnology Vol. 10(20), pp. 4183-4189

[14]. Kumar, J. V., Shahbazi, A. and Mathew, R., (1998), Bioconversion of solid food wastes to ethanol, Analysts, 123, pp 497-502.

[15]. Morris, W. and Sarad, R. P., (1990), Biotechnology of biomass conversion: fuels and chemicals from renewable resources, Open university press, Milton Keynes, 235.

[16]. Adams, M. R. and Flynn, G., (1982), Fermentation ethanol: an industrial profile, Tropical products institute, London, pp 1-19. 